\section{AIDS contact}

SIR - Anne McLaren (Nature 30 June, p.748) claims that "contact with semen may promote immune suppression" and implies that such contact may cause AIDS.

On the contrary, studies on the use of barrier contraception during heterosexual relations indicate increased breast cancer risk in women. This implies that contact with semen may actually be immunopotentiating, and help to prevent the development of breast cancer. Whatever the case, the important point is that women who contact semen during sexual relations do not become immunosuppressed and do not develop AIDS. Also, vasectomized men who form antibodies to their own sperm also do not develop AIDS.

Nevertheless, it certainly would be helpful to suggest, as Anne McLaren does, that male homosexuals use condoms to prevent transmission of possible AIDS agents. However, I don't think it scientifically objective to imply that contact with normal semen causes AIDS.

LouIS DeTolla

Division of Clinical Research,

Fox Chase Cancer Center,

Institute for Cancer Research,

Philadelphia, Pennsylvania 19111, USA

SIR - If, as noted recently (Nature 30 June, p.748 et seq.), contact with semen may promote immune suppression in humans and mice, why do heterosexual women and reproducing female mice not suffer from immune suppression? Or is it specific to males?

\section{CSIRO Molecular and \\ Cellular Biology Unit, PO Box 184, North Ryde (Sydney), New South Wales 2113, Australia}

ANNE MCLAREN REPLIES:

SIR - The imune suppression reported by Hurtenbach \& Shearer (J.exp.Med. 155 $1719 ; 1982$ ) was induced by spermatozoa introduced into the blood stream. Only male mice were tested but, as Sibatani implies above, it would be interesting to know if the effect is less marked in females. Alternatively, the female reproductive tract may have evolved mechanisms to minimize the entry of spermatozoa or sperm antigens into the blood stream, to guard against induced infertility and also perhaps AIDS. A slight degree of immune suppression, at least to minor histocompatibility antigens, does appear to be asociated with exposure of female mice to spermatozoa in the course of sterile matings (Lengerova \& Vojtiskova, Folia Biologica 8, 21; 1962). While we are still ignorant of what causes AIDS, any possible causative factor is surely worth investigating, and any possible form of protection is better than none.

ANNEMCLAREN

MRC Mammalian Development Unit,

4 Stephenson Way,

London NWI 2HE, UK

\section{Guidelines to radiation doses}

SIR - The news item "US academy sets guidelines"' (Nature 26 May, p.275), states that the National Academy of Sciences Report "for the purposes of its own study ... . selects $10^{-4}$ sieverts per year as the maximum acceptable average lifetime dose rate'. May I correct that misleading statement? You will find on page 216 of the academy report the following:

"The panel wishes to make clear that the individual-dose criterion of $10^{-4} \mathrm{~Sv} / \mathrm{yr}$ is not intended as an upper limit of radiation exposure. It is simply a goal against which a particular repository system performance can be compared. The dose value of $10^{-4} \mathrm{~Sv} / \mathrm{yr}$ is sufficiently low so as to provide reasonable assurance that no member of the public will be exposed to a radiation risk greater than that experienced and permitted from natural sources in day-to-day life. Other, higher limits (International Commission on Radiological Protection 1979) should be used to evaluate the upper levels of exposure estimated from the uncertainties inherent to the parameters used for calculating system performance."

Furthermore, pages 212-216 (Section 8.2) give a discussion as to how the panel arrived at a criterion of $10^{-4}$ sieverts per year and pages 216 and 217 (Section 8.3) discuss whether or not the value of $10^{-4}$ sieverts per year may be considered to be "as low as reasonably achievable".

JOHN M. MATUSZEK

Radiological Science Laboratory,

Department of Health,

Office of Public Health,

Albany, New York 12201, USA

\section{Pity the publisher}

SIR - I quite agree with A. J. Dessler (Nature 14 July, p.110). The authors of journal articles do not generally want protection from copying. It is the publishers who need the protection. They are the ones who are involved in the ever-increasing cost of producing journals, and who are seeing their subscription income continually eroded by large-scale photocopying. It is therefore reasonable that the party who is most interested in copyright protection should hold the copyright.

With regard to the burdensome administration of permissions, publishing organizations worldwide are now trying to set up licensing arrangements by which copying can be done with the minimum of formality and through which reasonable royalties can be paid to the copyright holder. Unfortunately they are meeting with a lot of opposition.

\section{The Institution of Electrical}

J.D. St AUBYN

Engineers,

PO Box 8

Southgate House,

Stevenage, Herts SGI $1 \mathrm{HQ}, \mathrm{UK}$

\section{How to swat flies}

SIR - The potential for house flies to spread disease has, of course, long been recognized. A fly, having crawled over human or animal faeces, may enter the house eventually to alight on exposed food. Usually the fly, attracted by light, whizzes up and down the window. Attempts to swat it dead are usually thwarted since the fly has a high-speed (millisecond) reflex system in its visual-brain-motor system so that it responds by taking off at an avoiding angle in response to a moving approaching swat entering its visual field.

In the interests of hygiene I have experimented on the most effective way of swatting. A piece of tissue paper is taken in each hand and the fly approached from the left and right, keeping the hands equidistant from the fly and moving to and fro slightly, then both hands simultaneously pounce. The fly cannot cope with this situation since its central nervous system circuitry is geared to avoid approaching movement in only one part of its visual field at a time. Two simultaneously approaching swats render the fly immobile, for its central nervous system now cannot compute at which angle to take off.

National Institute for Medical Research, The Ridgeway,

Mill Hill,

London NW7 1AA, UK

\section{In vitro mussel culture}

SIR - We believe Young and Williams' review' ${ }^{1}$ of Roberts' article ${ }^{2}$ involving our research ${ }^{3}$ missed the real point of the review. Unlike the British species Margaritifere margaritifera (L.) for which the fish host is evidently known, host(s) of most species are unknown. In the United States there are numerous endemic species which are extremely rare and for which there are no known host(s). Therefore, an in vitro culture method such as ours is the only hope for sustaining these species until a natural fish host or other host is found.

We have, and are now growing, juvenile mussels resulting from in vitro culture in the laboratory and in a field laboratory setting. It appears entirely feasible to apply our culture system to assure conservation of a species like $M$. margaritifera, although we would fully agree that natural expansion of popultions would be desirable, if possible.

BILLy G. ISOM

ROBERT G. HUDSON

Tennessee Valley Authority.

Muscle Shoals,

Alabama 35660, USA

\footnotetext{
Young, M.R. \& Williams, J.C. Nature 302, 372 (1983).

Roberts, R.J. Nature 302, 13 (1983).
}

Isom, B.C. \& Hudson, R.G. Nautilus \%, 147 (1983). 